\section{Stereological quantitation in cerebella}

\section{from people with schizophrenia}

\author{
BIRGITTE BO ANDERSEN and BENTE PAKKENBERG
}

Neuroanatomical, neuroimaging and behavioural reports of cerebellar involvement in cognitive and language functions increasingly implicate the cerebellum as the site of morphological changes occurring in schizophrenia and other psychiatric diseases (Heath et al, 1979; Weinberger et al, 1980; Courchesne et al, 1994). It has been suggested that classic cerebellar signs such as lack of coordination, limb movement abnormalities and dyscoordination, often reported in psychiatric diseases, could be caused by structural abnormality in the cerebellum. Autonomic, limbic and also higher cortical functions have been recognised as being modulated by the cerebellum (Hamilton et al, 1983; Schmahmann, 1991; Leiner et al, 1993; Katsetos et al, 1997).

The aim of this study was to apply recent stereological methods to cerebella from people with schizophrenia and an age- and gender-matched control group. The methods used were the Cavalieri principle (Gundersen et al, 1988b) to estimate the major volumes, the optical disector method (Gundersen, 1986) to obtain estimates of the numerical density of granular and Purkinje cells, and a combination of the two to obtain estimates of total cell numbers. The rotator method (Jensen \& Gundersen, 1993) was applied to estimate mean Purkinje cell volume.

\section{METHOD}

Cerebella from ten men with chronic schizophrenia but no neurological disorder (mean age at death 57.5 years) and ten male controls (mean age at death 56.2 years) were obtained post-mortem in accordance with the Danish law regarding autopsied human tissue. The brains were included in the study if fixed within $12-60 \mathrm{~h}$ postmortem. Exclusion criteria were presence of tumours or infection in the central nervous system, strokes, or any history of alcohol or drug misuse. After processing, embedding and staining, two brains were excluded owing to presence of cell necrosis, a well-known post-mortem phenomenon (Ikuta et al, 1963; Albrechtsen, 1977), leaving eight brains from the schizophrenia group and ten from the control group for further processing. To avoid the influence of gender differences, only male brains were included. Most of the control brains were from people who had died from sudden heart failure. Information about their life before admission to hospital was obtained from either close relatives or their general practitioner, thus enabling any patient with central nervous system symptoms to be excluded.

In the schizophrenia group the brain samples were taken from people with a DSM-III diagnosis of schizophrenia (American Psychiatric Association, 1980) who were in-patients at a psychiatric hospital in Denmark. All of these patients had been treated with neuroleptic drugs for a period of 3-30 years. The clinical data on both study groups are shown in Tables 1 and 2. The numbers of insulin comas and applications of electroconvulsive therapy (ECT) are given in Table 1, and postmortem interval, fixation time and agonal state are presented in Table 2.

\section{Neuropathology}

Tissue blocks were sampled from frontal, parietal, medial, temporal and occipital lobes, the insula, cingulate gyrus and hippocampus, and one or two tiers of mesencephalon. The tissue was processed routinely and embedded in paraffin wax. Sections $4 \mu \mathrm{m}$ thick were cut from all blocks for haematoxylin and eosin stains, and from selected areas for immunohistochemical investigation. Sections $8 \mu \mathrm{m}$ thick were cut from all blocks for Kluver-Barrera staining. Immunohistochemical stains were used for beta-amyloid (DAKO M0872; 1:200), tau (DAKO A0024, 1:50000), ubiquitin (DAKO Z0458, 1:5000) and alphasynuclein (Zymed zs 18-0215, 1:2000) (DAKO, Glostrup, Denmark; Zymed, San Francisco, CA, USA). The brain-stems were normal, including the pigmentation of the substantia nigra. There were no tumour or neuronal or glial inclusions, vasculitis or encephalitis.

\section{Anatomy}

The cerebellum consists of a median vermis and two lateral hemispheres (Braitenberg $\&$ 
Table I Treatment history of the eight patients in the schizophrenia group

\begin{tabular}{|c|c|c|c|c|c|c|}
\hline $\begin{array}{l}\text { Age } \\
\text { (years) }\end{array}$ & $\begin{array}{l}\text { Age at first admittance to } \\
\text { psychiatric hospital (years) }\end{array}$ & $\begin{array}{l}\text { Length of stay in psychiatric } \\
\text { hospital (years) }\end{array}$ & $\begin{array}{l}\text { Schizophrenia } \\
\text { subtype }\end{array}$ & $\begin{array}{c}\text { Duration of treatment with } \\
\text { neuroleptic drugs (years) }\end{array}$ & $\begin{array}{l}\text { Insulin comas } \\
\text { (n) }\end{array}$ & $\begin{array}{l}\text { ECT treatments } \\
\text { (n) }\end{array}$ \\
\hline 30 & 26 & I & Simplex & 3 & 0 & 0 \\
\hline 41 & 22 & 17 & Hebephrenic & 19 & 0 & 6 \\
\hline 45 & 20 & 23 & Paranoid & 23 & 28 & 40 \\
\hline 52 & 16 & 22 & Simplex & 25 & 38 & 22 \\
\hline 65 & 25 & 36 & Simplex & 30 & 0 & 0 \\
\hline 70 & 20 & 37 & Paranoid & 26 & 0 & 16 \\
\hline 78 & 22 & 56 & Simplex & 18 & 0 & 0 \\
\hline 79 & 41 & 34 & Paranoid & 24 & 28 & 21 \\
\hline
\end{tabular}

ECT, electroconvulsive therapy.

Table 2 Age, body height and weight, brain and cerebellum weight, cause of death, post-mortem delay in fixation, length of fixation and time from onset of terminal disease to death: comparison between schizophrenia group $(n=8)$ and control group $(n=10)$

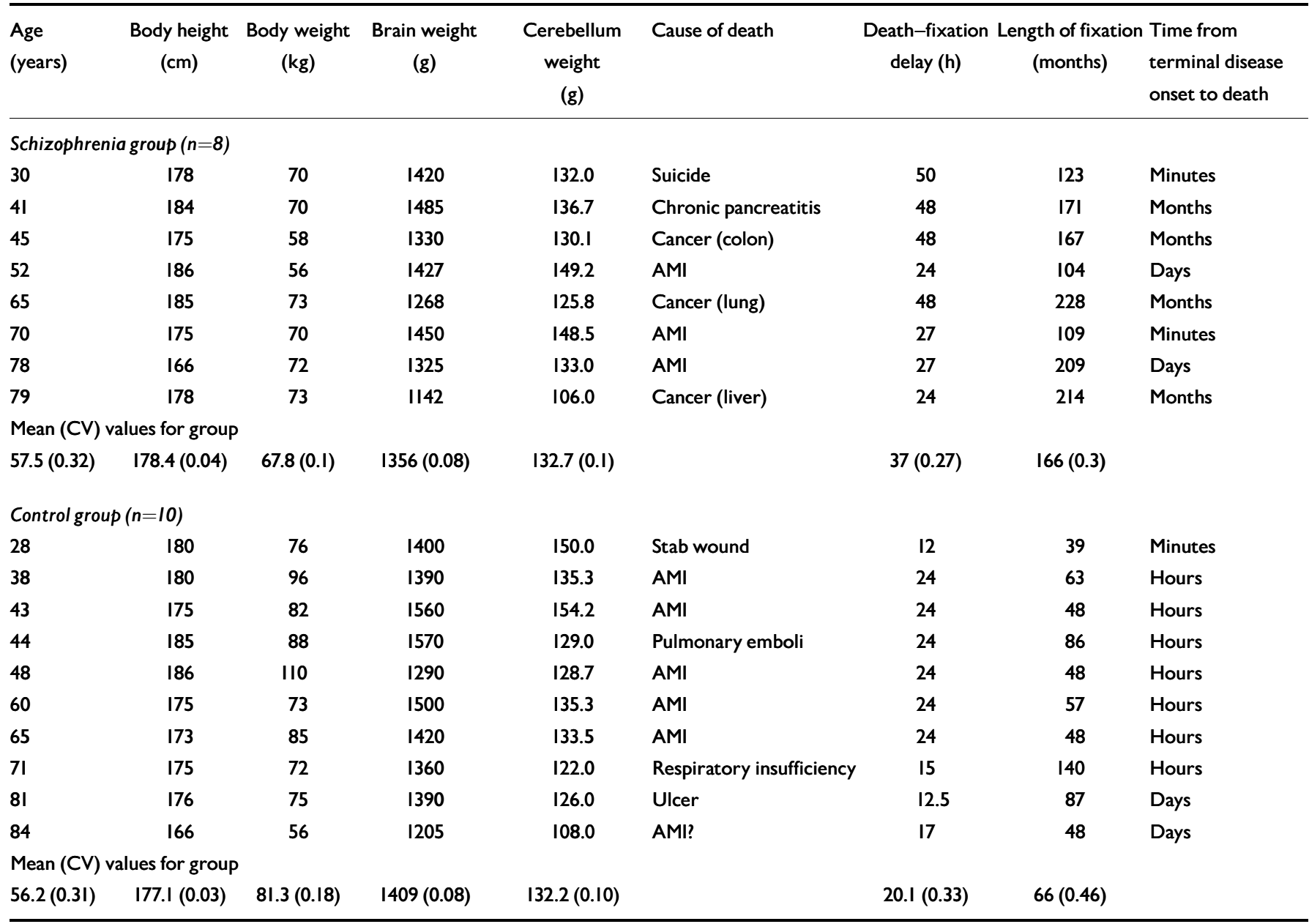

AMI, acute myocardial infarction; CV, coefficient of variation (s.d./mean).

Atwood, 1958). Five deep fissures divide the cerebellum into lobes and lobules: the primary fissure, the posterior superior fissure, the horizontal fissure, the prepyramidal fissure and the posterolateral fissure. Portions of the cerebellar hemispheres located rostrally to the primary fissure form the anterior lobe, whereas those between the primary and the posterolateral fissures constitute the posterior lobe.
The median vermis is divided into an anterior and a posterior part at the level of the primary fissure. The anterior vermis is the median part of the anterior lobe, and is often delineated by the 
indentation produced by the course of the medial branch of the superior cerebellar artery. The most caudal part, the flocculonodular lobe, is separated from the posterior lobe by the posterolateral fissure.

The motor representation in the human cerebellum is:

(a) the archicerebellum, the oldest zone, corresponding to the flocculonodular lobe and related to the vestibular system;

(b) the palaeocerebellum, referring primarily to the anterior lobe; this zone is functionally related to the spinal cord and is concerned with posture, muscle tone and gait;

(c) the neocerebellum, the evolutionarily most recent part, corresponding to the posterior lobe; this zone is functionally related to the cortico-ponto-cerebellar system, which exerts a regulating effect on discrete movements of the limbs and truncal movements.

The cortex is made up of three layers: the outer molecular layer, the middle Purkinje single cell layer, and the inner granular layer. The Purkinje cells have a large, clear nucleus with a deeply stained nucleolus and irregular Nissl granules. The granular layer is mainly composed of closely packed granule cells, in which the nuclei form the major constituent of the cell body. The sole output cell from the cerebellar cortex is the Purkinje cell that projects to the central cerebellar nuclei, which in turn provide efferents from the cerebellum.

\section{Experimental procedure}

For all stereological estimations to be based on unbiased principles, the procedures require isotropic, uniform random (IUR) sections, the only exceptions being estimations of volume and total cell numbers. Most biological structures are anisotropic, and to compensate for this the vertical section principle was applied (Baddeley et al, 1986). A vertical section is a plane section perpendicular to a given horizontal plane. The horizontal plane can be defined either by the tissue itself or generated artificially; it refers only to the orientation of the section. All sections must be cut perpendicular to the horizontal plane. The vertical direction must be known in all sections and the vertical sections must have a random position and orientation in two dimensions for the design to be unbiased. In practice, a cerebellum was dissected from the brain-stem at the level of the vestibulocochlear nerve and the surface was stained with waterproof ink in different colours to distinguish between the anterior and posterior hemisphere, the anterior and posterior part of the vermis, and the flocculonodular lobe. After removing the flocculonodular lobe, the cerebellum was embedded in $7 \%$ agar, and cut in a systematically random manner into slabs approximately $4 \mathrm{~mm}$ thick, using a cutting machine with a $4 \mathrm{~mm}$ interval. Each slab was used to estimate the volume of the different regions (see below). Starting randomly with either the first or the second slab, every second slab was cut systematically into $4 \mathrm{~mm}$ wide columns or rods and every $n$th rod was sampled to provide approximately five to eight rods from each of the five regions. The regions from which the rods were taken were identified by their coloured surfaces. Larger areas of white matter were removed and the rods rotated around their longitudinal axes and embedded in agar. The number of rods was decided on the basis of a pilot study (see Andersen et al, 1992). The flocculonodular lobe, consisting of three parts, was rotated clockwise, the first part randomly, the other two parts rotated $90^{\circ}$ and $180^{\circ}$ to the first, respectively. All were embedded in $7 \%$ agar and cut into $2 \mathrm{~mm}$ slabs. For more details regarding the vertical axis principle, see Baddeley et al (1986), and for further practical details of the stereological design, see Andersen et al (1992). The sampled rods were dehydrated and embedded in glycolmethacrylate for sectioning. From each three-dimensional uniformly random block, a central section $40 \mu \mathrm{m}$ thick was cut parallel to the vertical axis and stained with a modified Giemsa stain. On the basis of the results of a pilot study, the Giemsa stain was preferred because it gave a better contrast between cells than the Weil stain used in our earlier study.

\section{Estimation of total volumes}

Estimates of total cell number, $N$, were obtained by combining an estimate of the respective reference volumes, $V$ (ref.), using the Cavalieri method (Gundersen et al, $1988 a, b)$, and a separately obtained estimate of the three-dimensional numerical density, $N_{V}$, for each cell type. The macroscopic volumes were estimated from:

$$
V=t \times a(p) \times \Sigma P
$$

where $t$ is the average thickness of the cerebellar slabs (in this study, $4.1 \mathrm{~mm}$ ), $a(p)$ is the area associated with each point of the test grid $\left(4 \mathrm{~mm}^{2}\right.$ for anterior lobe, anterior and posterior vermis, $81 \mathrm{~mm}^{2}$ in posterior lobe) and $\Sigma P$ is the total number of points hitting the region of interest. The mean number of slabs in the anterior vermis, posterior vermis and the anterior lobe was 5 (range 4-7), and the mean number of slabs in the posterior lobe was 11 (range 9-13). The flocculonodular lobe was sampled in $2 \mathrm{~mm}$ slabs, and the mean number was 15 (range 14-18). The mean number of points hitting the regions was 80 in the anterior lobe and 50 in the anterior vermis, 80 in the posterior vermis and 250 in the large posterior lobe. The mean number of points in the flocculonodular lobe was 130 .

To estimate the volume of the granular and molecular layer and the white matter, the same sections as described below in 'Surface estimation' were used. Using point counting on the projected images with $a(p)=4 \mathrm{~cm}^{2}$ at a magnification of $\times 15$, $a(p)=1.78 \mathrm{~mm}^{2}$ at tissue level, a simple test grid was applied to the sections to generate the individual volume fractions $\left(V_{v}\right)$, where

$\Sigma P($ layer $) / \Sigma P($ region $)=V_{v}($ layer $/$ region $)$

which provides

$V($ layer $/$ region $)=V_{v}($ layer $/$ region $) \times V($ ref . $)$

The volume of the flocculonodular lobe was estimated using a test grid with $a(p)=4 \mathrm{~mm}^{2}$ and $t=2.0 \mathrm{~mm}$.

\section{Surface estimation}

Using the vertical section design on cerebellum (Baddeley et al, 1986; Andersen et al, 1992), the sampled rods were rotated randomly about their vertical axes. The rods were then embedded in agar, sectioned longitudinally and stained. On each section, the vertical axis was identifiable as the long axis of the rod. The surface area was estimated using a cycloid test system and a projecting microscope with a final magnification of $\times 15$ (for details, see Andersen $e t$ al, 1992). The surface (S) was estimated from the following equation:

\section{$S=2 \times \Sigma I /(\Sigma P \times l(p)) \times V($ cerebellum $)$}

where 2 is a constant valid for IUR testlines, $\Sigma P$ is the total number of points hitting the cerebellar tissue, $l(p)$ is the test line length per point, and $\Sigma I$ is the total number of intersections between the cycloid test lines and the cerebellar surface. 


\section{Layer thickness}

The thickness of the granular layer was estimated using the equation

$$
t(\text { layer })=V(\text { layer }) / S(\text { layer })
$$

where the pial surface area was used in both the molecular and the granular layers. The thickness was slightly underestimated because the granular layer is not situated directly under the pial surface.

\section{Estimation of total cell number}

The estimate of total cell number in a region as defined by the equation below is the product of the volume of each specific layer and the numerical density of a particular cell type in that layer:

$$
N=N_{V} \times V(\text { ref. })
$$

The Purkinje cells have a large, clear nucleus with one deeply stained nucleolus and irregular Nissl granules. Since a previous study showed that only $1 \%$ of the Purkinje cells have more than one nucleolus (Andersen et al, 1992), the nucleolus was used as the counting item. The granular layer is mainly composed of closely packed granule cells in which the nuclei form the major constituent of the cell body. In order to estimate numerical density of the two cell types the optical disector was applied. The optical disector equipment consists of a microscope with a high numerical aperture (1.40) and oil immersion $(\times 60$ or $\times 100$ ) objectives, which allow focusing on a thin focal plane inside a thick section. A video camera transmits the image to a screen where a counting frame is superimposed using the CAST-GRID PC program (Olympus, Denmark). The microscope stage is driven by a pair of stepping motors with preset steps of known length in the $x$ and $y$-directions. A microcator is used to measure stage movements in the $z$-axis.

A total of 20-30 rods, sampled from the five parts of cerebellum, were used to estimate the numbers of granule and Purkinje cells. For granule cell estimation the $\times 100$ objective was used and the disector height was $10 \mu \mathrm{m}$; Purkinje cells were estimated with a $\times 60$ objective and a disector height of $20 \mu \mathrm{m}$; the counting frames were $60 \mu \mathrm{m}^{2}$ and $25000 \mu \mathrm{m}^{2}$, respectively. One observer performed the counting on coded sections. The interrater reliability had been tested in a pilot study and was below $5 \%$.

Many counting fields contained no Purkinje cell. Therefore, in order to sample at least 50-60 cells, 150-300 disectors had to be sampled at the lowest possible magnification at which the nucleoli were distinguishable. The granular layer was used as a reference volume, which was obtained by using the upper right-hand corner of the counting frame as a reference point. The sampling scheme provided a coefficient of error (CE=s.e.m./mean) of 0.059 for global Purkinje cell estimation in the schizophrenia cerebellar samples and 0.065 for the control samples.

Owing to the uniformity of the granular layer, 100-200 cells counted in about 75150 disectors in each region were sufficient to give an estimate of global granule cell count with a coefficient of error of 0.047 in the schizophrenia samples and 0.043 in the controls.

\section{Mean volume of Purkinje cells}

Each sampled Purkinje cell was measured with a semi-automatic procedure using the menu-driven computer program, the rotator method (Jensen \& Gundersen, 1993), in which the volume of an arbitrary object can be estimated by rotating it about an arbitrary axis through a unique point in the object. The vertical axis is aligned parallel to the $y$-axis on the screen. Using the nucleolus as the unique point, the vertical axis is shown on the monitor by the interactive software. The top and bottom boundary points of the cell or nucleus are indicated by the operator, and the program systematically creates uniformly random test lines perpendicular to the vertical axis. Intersections between the lines and the boundaries are indicated by the operator and the volume is given in cubic micrometres. The volume of the perikaryon and cell nucleus was estimated for each sampled Purkinje cell. A mean of 345 Purkinje cells were counted and their volume estimated for each cerebellum.

\section{Statistics}

Differences between groups were judged by a two-tailed Student's unpaired $t$-test employing a significance level of 0.05 . The inter-individual variation, the coefficient of variation $(\mathrm{CV}=$ standard deviation/mean), is shown in parentheses following the group mean values.

The precision of individual estimates is indicated by the coefficient of error, which was $0.02-0.12$ in all macroscopic volume estimations. The coefficient of error for estimates of total number of Purkinje cells globally in both schizophrenia and control samples was 0.04-0.06, but was larger in sub-regions, where it varied from 0.16 to 0.25 for Purkinje cells and from 0.03 to 0.17 for the granule cells. The larger values were due partly to the sampling design, but also to the heterogeneous distribution of the cells.

The volume estimates of Purkinje cells were right-skewed and consequently analysed after logarithmic transformation. Mean values were reported as geometric means:

$$
\bar{x}=\exp [\operatorname{mean}(\ln x)]
$$

The inter-individual variation in groups is reported as the coefficient of variation after group mean values.

\section{RESULTS}

The mean total number of Purkinje cells was the same in the two groups $\left(31.5 \times 10^{6}, \mathrm{CV}=0.13\right.$ in the schizophrenia samples $v .28 .5 \times 10^{6}, \mathrm{CV}=0.19$ in the control samples; $P=0.20$ ), as was the mean total number of granule cells $\left(108.4 \times 10^{9}\right.$, $\mathrm{CV}=0.24$ in the schizophrenia samples $v$. $112.3 \times 10^{9}, \quad \mathrm{CV}=0.13$ in the control samples, $P=0.70$ ). No reduction of total Purkinje cell number was seen in any of the five sub-regions of the cerebellum (Table 3). The mean volume of the cerebellum in the schizophrenia samples $\left(126 \mathrm{~cm}^{3}, \mathrm{CV}=0.9\right)$ was not significantly different than in the control group (121 $\left.\mathrm{cm}^{3}, \mathrm{CV}=0.09 ; P=0.38\right)$, and neither was the volume of the total cerebellar cortex, white matter or central grey nuclei (Table 4). No significant difference in macroscopic volume was found in any of the five sub-regions. The most frequently reported findings in schizophrenia are volume and Purkinje cell loss in the anterior vermis. In this region the mean Purkinje cell number in the schizophrenia sample was $1.27 \times 10^{6}$ compared with $1.10 \times 10^{6}$ $(P=0.47)$ in the control group. The $95 \%$ confidence interval for the difference of means ranged from $0.31 \times 10^{6}$ more Purkinje cells in the controls to $0.64 \times 10^{6}$ more Purkinje cells in the schizophrenia group. The mean volume in the anterior vermis in the schizophrenia samples was $3.7 \mathrm{~cm}^{3}$ compared with $3.3 \mathrm{~cm}^{3}$ in the controls $(P=0.32)$, with a $95 \%$ CI for the difference of means ranging from $0.42 \mathrm{~cm}^{3}$ volume enlargement in controls to $1.23 \mathrm{~cm}^{3}$ enlargement in schizophrenia. 
Table 3 Total mean numbers of granule and Purkinje cells in the five different regions of the cerebellum: comparison between schizophrenia group $(n=8)$ and control group $(n=10)$

\begin{tabular}{|c|c|c|c|c|c|c|}
\hline & \multicolumn{3}{|c|}{ Purkinje cells $\left(10^{6}\right)$} & \multicolumn{3}{|c|}{ Granule cells $\left(10^{6}\right)$} \\
\hline & $\begin{array}{c}\text { Control } \\
\text { group } \\
\text { Mean (CV) }\end{array}$ & $\begin{array}{c}\text { Schizophrenia } \\
\text { group } \\
\text { Mean (CV) }\end{array}$ & $P$ & $\begin{array}{c}\text { Control } \\
\text { group } \\
\text { Mean (CV) }\end{array}$ & $\begin{array}{c}\text { Schizophrenia } \\
\text { group } \\
\text { Mean (CV) }\end{array}$ & $P^{\prime}$ \\
\hline Anterior lobe & $3.3(0.38)$ & $2.8(0.19)$ & 0.30 & $10419(0.26)$ & $9432(0.31)$ & 0.48 \\
\hline Posterior lobe & $22.5(0.19)$ & $25.9(0.14)$ & 0.09 & $93061(0.15)$ & $89892(0.24)$ & 0.72 \\
\hline Anterior vermis & I.I (0.40) & $\mathrm{I} .3(0.43)$ & 0.47 & $3690(0.27)$ & $3988(0.44)$ & 0.66 \\
\hline Posterior vermis & $\mathrm{I} .4(0.40)$ & $\mathrm{I} .3(0.3 \mathrm{I})$ & 0.77 & $4446(0.27)$ & $4475(0.34)$ & 0.97 \\
\hline Flocculonodular lobe & $0.3(0.49)$ & $0.3(0.28)$ & 0.62 & $65 \mathrm{I}(0.45)$ & $704(0.28)$ & 0.69 \\
\hline
\end{tabular}

CV, coefficient of variation (s.d./mean).

I. Two-tailed; no significant difference at the level $P<0.05$.
No overall statistically significant difference was found between the global mean perikaryon volume of the Purkinje cells in schizophrenia $\left(12400 \mu \mathrm{m}^{3}, \mathrm{CV}=\right.$ $0.24)$ and controls $\left(13800 \mu \mathrm{m}^{3}, \mathrm{CV}=0.22\right.$; $P=0.34$ ) nor in the volume of the Purkinje cell nucleus in schizophrenia $\left(1220 \mu \mathrm{m}^{3}\right.$, $\mathrm{CV}=0.22) \quad v$. controls $\left(1310 \mu \mathrm{m}^{3}, \mathrm{CV}=\right.$ $0.17 ; P=0.43$ ) (Fig. 1). The mean volumes in the five sub-regions are shown in Table 5. The granular and molecular layer is about $0.4-0.6 \mathrm{~mm}$ thick with little variation in the entire cerebellum, except in the flocculonodular lobe, in which it is thinner in both groups (see Table 4).

No statistically significant correlation was found between the total number of granule cells, the total number of Purkinje
Table 4 Surface area, volume and thickness of the molecular and granular layer in the cerebellum: comparison between schizophrenia group $(n=8)$ and control group $(n=10)$

\begin{tabular}{|c|c|c|c|c|c|}
\hline \multirow[b]{2}{*}{ Pial surface area $\left(\mathrm{cm}^{2}\right)$} & \multicolumn{2}{|c|}{$\begin{array}{c}\text { Schizophrenia group } \\
\text { Mean (CV) }\end{array}$} & \multicolumn{2}{|c|}{$\begin{array}{c}\text { Control group } \\
\text { Mean (CV) }\end{array}$} & \multirow{2}{*}{$\begin{array}{c}P^{\prime} \\
0.95\end{array}$} \\
\hline & 910 & $(0.18)$ & 914 & $(0.14)$ & \\
\hline Cerebellar volume $\left(\mathrm{cm}^{3}\right)$ & 126 & $(0.09)$ & $|2|$ & $(0.09)$ & 0.38 \\
\hline Central grey nuclei volume $\left(\mathrm{cm}^{3}\right)$ & 1.9 & $(0.48)$ & & I (0.33) & 0.64 \\
\hline Total volumes $\left(\mathrm{cm}^{3}\right)$ & 91.3 & $3(0.11)$ & 89.8 & $8(0.09)$ & 0.73 \\
\hline Anterior lobe & 9.0 & $(0.20)$ & & $7(0.23)$ & 0.76 \\
\hline Posterior lobe & 74.0 & $(0.13)$ & 73.0 & $0(0.10)$ & 0.75 \\
\hline Anterior vermis & 3.7 & $7(0.26)$ & & $3(0.20)$ & 0.32 \\
\hline Posterior vermis & 3.8 & $3(0.25)$ & & I (0.17) & 0.38 \\
\hline Flocculonodular lobe & 0.7 & $7(0.13)$ & & $7(0.24)$ & 0.97 \\
\hline White matter & 32.6 & $6(0.2 \mathrm{I})$ & 29.2 & $2(0.19)$ & 0.27 \\
\hline \multicolumn{6}{|c|}{ Average thickness of molecular layer $(\mu \mathrm{m})$} \\
\hline Anterior lobe & 600 & $(0.20)$ & 610 & $(0.18)$ & 0.91 \\
\hline Posterior lobe & 570 & $(0.12)$ & 580 & $(0.10)$ & 0.77 \\
\hline Anterior vermis & 610 & $(0.16)$ & 620 & $(0.29)$ & 0.97 \\
\hline Posterior vermis & 580 & $(0.25)$ & 670 & $(0.23)$ & 0.20 \\
\hline Flocculonodular lobe & 420 & $(0.18)$ & 430 & $(0.35)$ & 0.83 \\
\hline \multicolumn{6}{|c|}{ Average thickness of granular layer $(\mu \mathrm{m})$} \\
\hline Anterior lobe & 422 & $(0.17)$ & 420 & $(0.17)$ & 0.95 \\
\hline Posterior lobe & 450 & $(0.19)$ & 402 & $(0.16)$ & 0.20 \\
\hline Anterior vermis & 485 & $(0.20)$ & 460 & $(0.24)$ & 0.64 \\
\hline Posterior vermis & 497 & $(0.17)$ & 488 & $(0.2 I)$ & 0.86 \\
\hline Flocculonodular lobe & 410 & $(0.32)$ & 380 & $(0.32)$ & 0.59 \\
\hline
\end{tabular}

CV, coefficient of variation (s.d./mean).

I. No significant difference was found between the two groups in any of the five regions or in the global cerebellum. cells, or the mean Purkinje cell perikarya and nuclei volumes, and fixation time and medication. However, a statistically significant correlation was found between the post-mortem interval and the total number of granule cells in the schizophrenia group (coefficient of correlation, $r=-0.56$, $P=0.015$ ) but not in the control group. Furthermore, we found a statistically significant correlation between the volume of the Purkinje cell perikarya and the Purkinje cell nuclei, and the cerebellar weight in both groups: schizophrenia group $r($ perikaryon $)=0.80, P=0.018, \quad r($ nuclei $)=$ $0.78, P=0.02$; control group, $r$ (perikaryon) $=0.91, P=0.0003, r$ (nuclei) $=0.77, P=0.009$. Since the two regression lines did not differ, the analysis is performed on the combined material (Fig. 2).

\section{Shrinkage}

During the preparation of the rods for histological processing, extra rods were taken to measure shrinkage. The area of the rods was measured before and after histological processing and compared. In accordance with other studies, no net shrinkage was detectable (Pakkenberg et al, 1989; Brændgaard et al, 1990). A large variation between the brains was observed; however, no global difference was found between the schizophrenia group and the control group.

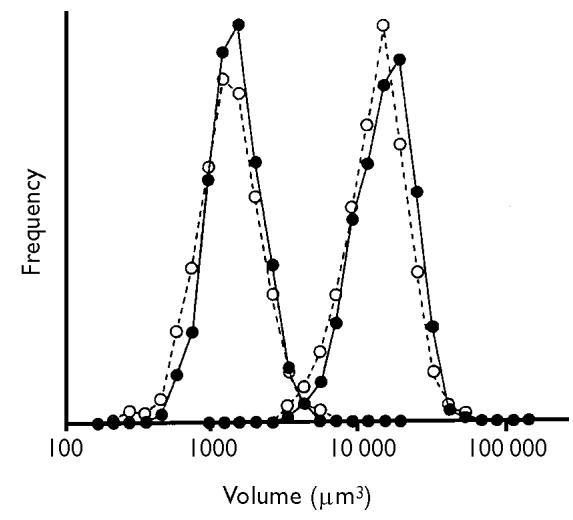

Fig. I Average size distribution of Purkinje cell perikarya (right-hand peaks) and nuclei (left-hand peaks) in the control group (๑) and in the schizophrenia group $(\bigcirc)$. All Purkinje cells sampled for number estimation were volume-estimated (a mean of 345 Purkinje cells per cerebellum). Since the Purkinje cell volume turned out to be right-skewed, the volumes are reported on a logarithmic scale. No difference is observed in Purkinje cell volumes in the schizophrenia group $(n=8)$ compared with the control group $(n=10)$. 
Table 5 Perikaryon and nucleus volumes in Purkinje cells in the five different regions of the cerebellum: comparison between schizophrenia group $(n=8)$ and control group $(n=10)$

\begin{tabular}{|c|c|c|c|c|c|c|}
\hline & \multicolumn{3}{|c|}{ Perikaryon volume $\left(\mu \mathrm{m}^{3}\right)$} & \multicolumn{3}{|c|}{ Nucleus volume $\left(\mu \mathrm{m}^{3}\right)$} \\
\hline & $\begin{array}{c}\text { Control } \\
\text { group } \\
\text { Mean (CV) }\end{array}$ & $\begin{array}{c}\text { Schizophrenia } \\
\text { group } \\
\text { Mean (CV) }\end{array}$ & $P^{\prime}$ & $\begin{array}{l}\text { Control } \\
\text { group } \\
\text { Mean (CV) }\end{array}$ & $\begin{array}{c}\text { Schizophrenia } \\
\text { group } \\
\text { Mean (CV) }\end{array}$ & $P^{\prime}$ \\
\hline Anterior lobe & $13737(0.27)$ & $13335(0.26)$ & 0.82 & $1342(0.21)$ & $1297(0.27)$ & 0.77 \\
\hline Posterior lobe & $13883(0.22)$ & $12405(0.25)$ & 0.33 & $1309(0.16)$ & $1209(0.23)$ & 0.39 \\
\hline Anterior vermis & $13900(0.24)$ & II $207(0.2 \mathrm{I})$ & 0.07 & $1292(0.22)$ & $\mathrm{II} 36(0.23)$ & 0.25 \\
\hline Posterior vermis & $12516(0.24)$ & II $480(0.22)$ & 0.45 & $1292(0.24)$ & $1207(0.20)$ & 0.54 \\
\hline Flocculonodular lobe & $12300(0.29)$ & $1 \mathrm{I} 815(0.27)$ & 0.69 & $1326(0.25)$ & $1290(0.33)$ & 0.84 \\
\hline
\end{tabular}

$\mathrm{CV}$, coefficient of variation (s.d./mean).

I. Two-tailed. There is no significant difference at the level $P<0.05$.

\section{DISCUSSION}

The most accepted pathological finding in the cerebellum in cases of schizophrenia is vermal atrophy, which was not found in this study. The two sets of brains are not directly comparable since almost all the brains in the control group were taken from men who died from sudden heart failure, whereas in the schizophrenia group deaths were from various causes, including cancer. It is unknown how chronic illness might influence any measurement, but no difference in regional or total volumes, cell numbers or Purkinje cell size was found in the

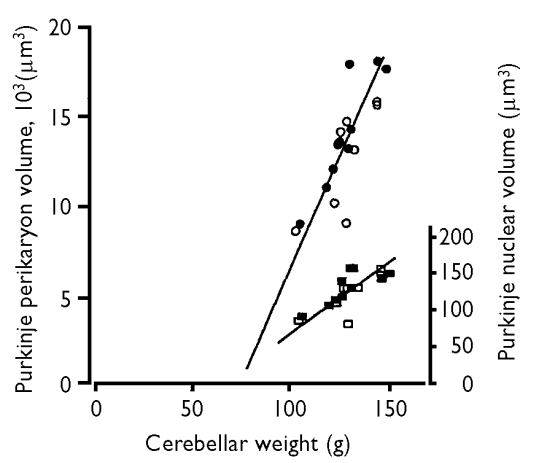

Fig. 2 The correlation between cerebellar weight and the volume of Purkinje cell perikarya in the control group $(\bullet)$ and the schizophrenia group $(O)$ (left-hand vertical axis), and the Purkinje nuclear volume in the control group ( $\square$ ) and schizophrenia group ( $\square$ ) (right-hand axis). The coefficient of correlation for the combined groups was highly significant, with coefficients of correlation for perikarya cell volumes $r$ (perikarya $)=0.82, P<0.001$, and $r$ (nuclei) $=0.83, P<0.001$. schizophrenia group compared with the controls.

\section{Previous studies of the cerebellum}

Computed tomography (CT) studies of patients with schizophrenia have reported a reduction in dorsal vermal volume of $10 \%$ or more in patients compared with controls (for review see Snider, 1982). Heath et al (1979) reported predominantly vermal 'atrophy' in 34 out of 85 patients, and Lippman et al (1982) found a $17 \%$ smaller vermis in patients compared with controls, and one or more abnormal dimensions in cerebella in 16 of 54 cases of schizophrenia. Weinberger et al (1979), also using CT scans, found an abnormally small cerebellar vermis in 9 out of 60 cases of schizophrenia. In all these studies the estimation was made by visual assessment. Using planimetry in a magnetic resonance imaging (MRI) study, Nasrallah et al (1991) reported larger cerebellar structures in men with schizophrenia compared with controls, whereas Nopoulos et al (1999)-also using MRI, but applying automated methods - showed no group difference in cases of schizophrenia compared with controls.

In a non-uniform morphometric study of the anterior cerebellar vermis, Weinberger et al (1980) found that the area of the vermis was smaller in 5 out of 12 cerebella from individuals with schizophrenia than in any of the 7 control subjects. Reyes \& Gordon (1981) reported the linear density of Purkinje cells to be decreased in the cerebellar vermis in 8 cases of schizophrenia compared with 12 controls. Stevens (1982), using conventional counting/quantitative methods, reported either gliosis or Purkinje cell loss in a proportion of cerebella from patients with schizophrenia. Tran et al (1998), measuring the cross-sectional area of Purkinje cells using computer-assisted image analysis, reported reduced Purkinje cell size in the superior vermis in elderly patients with schizophrenia, but did not find any differences in linear density between patients and controls.

\section{Clinical data}

Kinney et al (1999) conducted a clinical study including 54 persons with schizophrenia and 73 of their relatives, 37 persons with bipolar affective disorder, and 24 persons with a history of substance abuse. The people with schizophrenia and their relatives had a higher proportion of cerebellar symptoms, especially balance abnormality, than did the other patients and the control group. Rubin et al (1994) conducted a study of 44 patients with a first episode of schizophrenia or schizophreniform disorder (mean age 27.5 years), and a control group of 24. All patients had a full neurological examination when first admitted to hospital, and were found to have more neurological abnormalities than the control group, but the only statistically significant abnormality was seen in cerebellar functions. These data could indicate cerebellar involvement in schizophrenia, primarily vermal atrophy.

\section{Cerebellum and cognitive function}

Although it is generally recognised that the projection from the cerebellum reaches the motor areas of the frontal lobe (Brodmann areas 4 and 6), it is not as widely recognised that the cerebellar projection also reaches some prefrontal areas (Leiner et al, 1993). Even in the complete absence of any motor activity, the cerebellum is activated when humans perform certain cognitive and language tasks. The inferior lateral part of the cerebellum in particular is markedly activated during both mental counting and mental imagery (Petersen \& Fiez, 1993; Ryding et al, 1993). A positron emission tomography study by Andreasen et al (1996) points to a dysfunctional prefrontal-thalamocerebellar circuitry in schizophrenia. $\mathrm{Pa}$ tients with cerebellar abnormalities found post-mortem, such as agenesis or hypoplasia of the cerebellum, paraneoplastic degeneration and dentate-rubro-pallido-lusian atrophy, have been described as 'mentally abnormal' (for review see Katsetos et al, 
1997). Several papers have indicated cerebellar involvement in autism (Piven et al, 1992; Courchesne et al, 1994), and atrophy has been described by Courchesne et al (1994), who suggested that cerebellar maldevelopment contributes to the cognitive and social deficits characteristic of this disease. The patients' inability to perform rapid attention shifts between auditory and visual stimuli might be one reason for their social and cognitive problems.

\section{Evaluation of results}

The patients in this study all had severe schizophrenia and had a long history of neuroleptic treatment (3-30 years). None of the parameters tested (the total volume of the cerebellum, the total number of granule and Purkinje cells, the mean volume of Purkinje cells, and the mean numbers of granule and Purkinje cells in sub-regions of cerebellum) showed any statistically significant difference between the two groups. However, it should be emphasised that the two groups are small, and that previous studies reporting significant differences did not find changes in all cases of schizophrenia.

We found a significant correlation in both groups between the volume of the Purkinje cells (both perikarya and nuclei) and the weight of the cerebellum. This correlation could be interpreted in several ways: either the volume of the cells increases differentially owing to a number of uncontrolled factors that lead to fluid uptake (such as agonal events, post-mortem changes and fixation), or a biological relationship exists between the volume of cerebellum and the volume of the cells, so individuals with a large cerebellum also have large Purkinje cells. This point needs further clarification in a material with fewer variables.

This study presents estimates of the total number of Purkinje and granule cells in the cerebella of eight individuals with schizophrenia compared with ten controls. No problem was encountered in identifying the different cell types; although a few ectopic granule cells can be found outside the granular layer, they have no impact on the final estimates compared with the total granule cell number.

The result should be considered a rough estimate of the population means of the two groups, since the groups were very small. However, the quantitation provided estimates obtained from methods based on unbiased principles. Our data do not

\section{CLINICAL IMPLICATIONS}

No global or regional atrophy was found in the cerebellar cortex of patients with schizophrenia.

- There was no evidence of loss of neurons in the anterior vermis in this severely affected group of patients.

- The cerebellar symptoms in some cases of schizophrenia may be caused by factors that do not lead to neuron loss.

\section{LIMITATIONS}

- The sample size does not exclude small differences in volumes and cell number in the different regions of the cerebellum.

- Although unbiased designs are applied, differential regional shrinkage can occur.

- The two groups are not directly comparable since almost all the people in the control group died from sudden heart failure, as opposed to those in the schizophrenia group who died from various causes, including cancer. It is unknown how chronic illness might influence the measurements of cell density and cell size.

BIRGITTE BO ANDERSEN, MD, BENTE PAKKENBERG, MD, Research Laboratory for Stereology and Neuroscience, Bispebjerg Unversity Hospital, Copenhagen, and Stereological Research Laboratory, Aarhus University, Aarhus, Denmark

Correspondence: Birgitte Bo Andersen, Research Laboratory for Stereology and Neuroscience, Bispebjerg University Hospital, Bispebjerg Bakke 23, DK-2400 Copenhagen NV, Denmark. Tel: +45 353। 6420; fax: +45 353I 6434; e-mail: forsklab@bbh.hosp.dk

(First received 30 January 2002, final revision 28 August 2002, accepted 12 November 2002)

exclude a minor to moderate cell or volume loss, but major volume or cell loss in the cerebellar cortex - as proposed by others as a pathogenic factor in schizophrenia seems unlikely. Cerebellar dysfunction caused by undetected morphologic change is still a possibility. For example, the number of synapses or cells in the deep cerebellar nuclei and the number of glial cells were not estimated in this material and their relevance is therefore unknown.

\section{ACKNOWLEDGEMENTS}

The authors thank H. J. G. Gundersen for his help and advice regarding experimental design and statistical analysis, and Lykke Steffensen, Susanne Primdahl, Hans Jørgen Jensen and Ulla Vonger for their skilful technical assistance. The authors also thank the Ferd. and Ellen Hindsgaul Foundation, and the Director Emil C. Hertz and wife Inger Hertz Foundation for financial support. Approved by the local ethics committee (no. II-0I0/0I).

\section{REFERENCES}

Albrechtsen, R. (1977) The pathogenesis of acute selective necrosis of the granular layer of the human cerebellar cortex. Acta Neuropathologica (Berlin), 37 3I-34.

American Psychiatric Association (1980) Diagnostic and Statistical Manual of Mental Disorders (3rd edn). (DSM-III).Washington, DC: APA

Andersen, B. B., Korbo, L. \& Pakkenberg, B. (1992) A quantitative study of the human cerebellum with unbiased stereological techniques. Journal of Comparative Neurology, 326, 549-560.

Andreasen, N. C., O'Leary, D. S., Cizadl, T., et al (1996) Schizophrenia and cognitive dysmetria: a positron-emission-tomography study of dysfunctional prefrontal-thalamic-cerebellar circuitry. Proceedings of the Academy of Natural Sciences of Philadelphia, 93, 9985-9990.

Baddeley, A. J., Gundersen, H. J. G. \& Cruz-Orive, L. M. (1986) Estimation of surface area from vertical sections. Journal of Microscopy, 142, 259-276.

Brændgaard, H., Evans, S. M., Howard, V. C., et al (1990) The total number of neurons in the human neocortex unbiasedly estimated using optical disectors. Journal of Microscopy, I57, 285-304. 
Braitenberg, V. \& Atwood, R. P. (1958) Morphological observations on the cerebellar cortex. Journal of Comparative Neurology, 109, I-33

Courchesne, E., Townsend, J., Akshoomoff, N. A., et al (1994) Impairment in shifting attention in autistic and cerebellar patients. Behavioural Neuroscience, 108 848-865.

Gundersen, H. J. G. (1986) Stereology of arbitrary particles. A review of unbiased number and size estimators and the presentation of some new ones, in memory of William R. Thomson. Journal of Microscopy, 143, 3-45.

_ \& Jensen, E. B. (1987) The efficiency of systematic sampling in stereology and its prediction. Journal of Microscopy, 147, 229-263.

_ , Bendtsen, T. F., Korbo, L., et al (1988a) Some new, simple and efficient stereological methods and their use in pathological research and diagnosis. APMIS, 96, 379-394.

_ , Bagger, P., Bendtsen, T. F., et al (1988b) The new stereological tools: disector, fractionator, nucleator and point sampled intercepts and their use in pathological research and diagnosis. APMIS, 96, 857-88I.

Hamilton, N. G., Frick, R. B., Takahashi, T., et al (1983) Psychiatric symptoms and cerebellar pathology. American Journal of Psychiatry, 140, 1322-1326.

Heath, R. G., Franklin, D. E. \& Shraberg, D. (1979) Gross pathology of the cerebellum in patients diagnosed and treated as functional psychiatric disorders. Journal of Nervous and Mental Disease, 167, 585-592.

Ikuta, F., Hirano, A. \& Zimmerman, H. M. (1963) An experimental study of post-mortem alterations in the granular layer of cerebellar cortex. Journal of Neuropathology and Experimental Neurology, 22 58|-593.
Jensen, E. B.V. \& Gundersen, H. J. G. (1993) The rotator. Journal of Microscopy, I70, 35-44.

Katsetos, C. D., Hyde, T. M. \& Herman, M. M. (1997) Neuropathology of the cerebellum in schizophrenia, an update: 1996 and future directions. Biological Psychiatry, $42.213-224$.

Kinney, D. K., Yurgelun-Todd, D. A. \& Woods, B.T (1999) Neurologic signs of cerebellar and cortical sensory dysfunction in schizophrenics and their relatives. Schizophrenia Research, 35, 99-104.

\section{Leiner, H. C., Leiner, A. L. \& Dow, R. S. (1993)}

Cognitive and language functions of the human

cerebellum. Trends in Neurosciences, II, 444-447.

Lippman, S., Manshadi, M., Baldwin, H., et al (1982) Cerebellar vermis dimensions on computerized tomographic scans of schizophrenic and bipolar patients. American Journal of Psychiatry, 139, 667-668.

Nasrallah, U. M., Schwarzkopf, S. B., Olson, S. C., et al (1991) Perinatal brain injury and cerebral vermal lobules I-X in schizophrenia. Biological Psychiatry, 29 $567-574$

Nopoulos, P. C., Ceilley, J.W., Gailis, E. A., et al (1999) An MRI study of cerebellar vermis morphology in patients with schizophrenia: evidence in support of the cognitive dysmetria concept. Biological Psychiatry, 46, $703-711$.

Pakkenberg, B., Evans, S. M., Møller, A., et al (1989) Total number of neurons in human neocortex related to age and sex estimated by way of optical disectors. Acta Stereologica, 8, 25I-256.

Petersen, S. E. \& Fiez, J. A. (1993) The processing of single words studied with positron emission tomography. Annual Review of Neuroscience, 16, 509-530.
Piven, J., Nehme, E., Simon, J., et al (1992) Magnetic resonance imaging in autism: measurement of the cerebellar pons, and fourth ventricle. Biological Psychiatry, 31, 491-504.

Reyes, M. G. \& Gordon, A. (1981) Cerebellar vermis in schizophrenia. Lancet, ii, 700-70I.

Rubin, P., Vorstrup, S., Hemmingsen, R., et al (1994) Neurological abnormalities in patients with schizophrenia or schizophreniform disorder at first admission to hospital: correlations with computerized tomography and regional cerebral blood flow findings. Acta Psychiatrica Scandinavica, 90, 385-390.

Ryding, E., Decety, J., Sjöholm, H., et al (1993) Moto imagery activates the cerebellum regionally. A SPECT rCBF study with ${ }^{99 m} \mathrm{~m}$ c-HMPAO. Cognitive Brain Research, I. 94-99.

Schmahmann, J. D. (1991) An emerging concept. The cerebellar contribution to higher function. Archives of Neurology, 48, 1178-1187.

Snider, S. R. (1982) Cerebellar pathology in schizophrenia - cause or consequence? Neuroscience and Biobehavioral Reviews, 6, 47-53.

Stevens, J. R. (1982) Neuropathology of schizophrenia Archives of General Psychiatry, 39, |131-1139.

Tran, K. D., Smutzer, G. S., Doty, R. L., et al (1998) Reduced Purkinje cell size in the cerebellar vermis of elderly patients with schizophrenia. American Journal of Psychiatry, 155, 1288-1290.

Weinberger, D. R., Kleinman, J. E., Luchins, D. J., et a (1980) Cerebellar pathology in schizophrenia: a controlled post-mortem study. American journal of Psychiatry, I37, 359-361.

— , Torrey, E. F. \& Wyatt, R. J. (1979) Cerebellar atrophy in chronic schizophrenia. Lancet, i, 718-719. 